\title{
GERMANIDADE: ASPECTOS CULTURAIS E IDENTITÁRIOS EM MARECHAL CÂNDIDO RONDON-PR
}

\author{
Luana Caroline Künast Polon ${ }^{1}$ \\ Paulo Henrique Heitor Polon ${ }^{2}$
}

\begin{abstract}
RESUMO: Este artigo se propõe a discutir como os discursos que se referem à germanidade estão presentes no cotidiano e na paisagem de Marechal Cândido Rondon, no extremo oeste do Paraná. A identidade germânica se manifesta através de aspectos culturais, sendo materializada na paisagem do município. Torna-se pertinente, neste contexto, analisar as investidas criadas pelo Poder Público, mas também pelos indivíduos cotidianamente, com a finalidade de manter a memória germânica viva, não permitindo que esta caia no esquecimento conforme passam as gerações, mas possibilitando que a memória reviva através das manifestações culturais. Para elaboração deste artigo foram utilizados referenciais bibliográficos, documentos históricos, além das próprias percepções de quem vivenciou as dinâmicas do ambiente em questão. Assim como outras cidades germânicas, Marechal Cândido Rondon preserva elementos culturais em favor da manutenção das memórias, mas não apenas limitando-se a isto, também visando o desenvolvimento turístico do município, constituindo um verdadeiro projeto de germanização.
\end{abstract}

Palavras-chave: Marechal Cândido Rondon; Identidade; Germanidade.

\section{GERMANNESS: CULTURAL ASPECTS AND IDENTITY OF MARECHAL CÂNDIDO RONDON-PR}

\begin{abstract}
This article aims to discuss how the speeches that refer to Germanity are present in the daily life and landscape of Marechal Cândido Rondon, in the extreme
\end{abstract}

\footnotetext{
1 Mestre em Geografia (2014), Especialista em Neuropedagogia (2013), Especialista em Educação Profissional e Tecnológica (2018) e Graduada em Licenciatura em Geografia (2011). Professora Formadora I - Universidade Federal do Pampa - UNIPAMPA/Universidade Aberta do Brasil - UAB. Concentra seus estudos nas áreas de Geografia Humana e Ensino de Geografia. Tem experiência como Professora Universitária e da Educação Básica, Orientadora e Supervisora de Estágio em Licenciatura, Orientadora do Plano de Desenvolvimento da Escola - PDE, e ainda como Redatora de Conteúdos para sites de Educação. Integrante dos grupos de pesquisa Cultura, Fronteira e Desenvolvimento Regional e Engeo - Ensino e Práticas de Geografia. E-mail: luanacaroline.geografia@gmail.com

2 Professor do Instituto Federal de Educação, Ciência e Tecnologia do Rio Grande do Sul - IFRS Campus Ibirubá. Docente nos cursos Médio Integrado, Subsequente, Graduação (Licenciatura em Matemática, Engenharia Mecânica, Agronomia e Ciência da Computação) e Pós-Graduação em Ensino, Linguagens e suas Tecnologias. Coordenador do curso de Especialização em Ensino, Linguagens e suas Tecnologias do IFRS Campus Ibirubá-RS. Mestre em Sociedade, Cultura e Fronteiras - UNIOESTE (2013). Especialista em Educação Profissional e Tecnológica - Faculdade São Braz (2018); Especialista em Neuropedagogia - Faculdade ALFA (2013). Licenciado e Bacharel em Ciências Sociais - UEL (Licenciatura - 2010; Bacharelado - 2011). Concentra seus estudos na área de Sociologia, Sociologia Urbana, Antropologia e Interdisciplinar com ênfase nos temas: Patrimônio, Memória, Imaginários, Sociabilidades e em Ensino de Sociologia. E-mail: pauloh2polon@gmail.com
} 
west of Paraná. The Germanic identity is manifested through cultural aspects, being materialized in the landscape of the municipality. It is pertinent, in this context, to analyze the attacks created by the Public Power, but also by individuals on a daily basis, in order to keep the Germanic memory alive, not allowing it to fall into oblivion as the generations pass, but allowing the memory to revive through cultural manifestations. To prepare this article, bibliographic references, historical documents were used, in addition to the perceptions of those who experienced the dynamics of the environment in question. Like other German cities, Marechal Cândido Rondon preserves cultural elements in favor of maintaining memories, but not only limiting himself to this, but also aiming at the tourist development of the municipality, constituting a true Germanization project.

Keywords: Marechal Cândido Rondon; Identity; Germanness.

\section{INTRODUÇÃO}

Marechal Cândido Rondon é um município localizado na região Oeste do Estado do Paraná, tendo sido emancipado no ano de 1960 e, amplamente colonizado por imigrantes descendentes de europeus, especialmente os de origem alemã. Ao se andar pelas ruas da cidade, não é difícil encontrar traços que rememoram esta origem histórica. Não apenas a arquitetura em estilo germânico, mas também as festividades, os costumes alimentares e musicais são elementos de representação cultural dos indivíduos que impulsionaram o processo de ocupação da região no século XX. Além disso, é relevante frisar ainda que existem políticas públicas voltadas ao resgate e valorização dos referidos aspectos culturais, como forma de reafirmar uma caracterização identitária.

Apesar da miscigenação que ocorreu com a integração na sociedade rondonense de diversos outros grupos étnicos, a presença dos elementos relativos à cultura germânica ainda predomina nas ações de base turística e arquitetônica. Exemplo disso, são as construções, tanto antigas, quanto mais recentes, e que se remetem ao estilo arquitetônico característico da Alemanha, o enxaimel. Do mesmo modo, existem festividades específicas, como a Oktoberfest, cujo sentido original é a festa da cerveja, comum principalmente em Munique, na Alemanha. A linguagem também mostra traços da memória cultural alemã, especialmente com os dialetos falados no município, os quais misturam elementos da linguagem brasileira com a alemã, criando uma forma de comunicação própria dos grupos de descendentes de alemães no Sul do Brasil. 
É interessante, no entanto, observar que existe um processo de perpetuação da disseminação da cultura germânica tanto pelas pessoas no cotidiano, quanto pelo próprio Poder Público, a partir de incentivos diversos para divulgação e manutenção desta cultura, apesar do fato de as gerações mais recentes terem abdicado parte destes elementos culturais, uma vez que no contexto contemporâneo surgem múltiplas possibilidades de novas identificações, e a identidade teoricamente sofrer um processo de fragilização. Porém, cabe ressaltar que isso não é uma regra, uma vez que diante da multiplicidade, a necessidade de segurança representada por uma identidade concreta ainda é um anseio social. Assim, as identidades também podem se fortalecer nesse contexto.

\section{IDENTIDADES E CULTURA: BREVE DEBATE CONCEITUAL}

Pode-se dizer que o conceito de cultura é polissêmico, ou seja, existem diversos sentidos atrelados à este termo. Assim, conforme estudo de Canclini (2009, p. 43) existem quatro principais vertentes nos estudos sobre cultura. A primeira delas "vê a cultura como a instância em que cada grupo organiza sua identidade". Neste sentido, não há grandes diferenças do pensamento clássico sobre cultura, desde o século XIX os antropólogos já avaliam a cultura desta forma, como modo de organização social finalizado na construção das identidades. A segunda vertente refere-se à cultura "vista como uma instância simbólica da produção e reprodução da sociedade" (CANCLINI, 2009, p. 45). Esta definição possui suas limitações, pois no interior de uma sociedade as práticas dos sujeitos possuem uma dimensão cultural, mas é pertinente analisar que nem todas as práticas sociais são cultura.

A terceira direção de pensamento analisada pelo autor, "fala da cultura como uma instância de conformação do consenso e da hegemonia, ou seja, de configuração da cultura política e também da legitimidade” (CANCLINI, 2009, p. 46). A apropriação da cultura em momentos específicos é uma alternativa de demonstração e imposição de poder. Já, a quarta vertente percebe a "cultura como dramatização eufemizada dos conflitos sociais" (CANCLINI, 2009, p. 46). Assim, a cultura seria uma espécie de representação teatral, onde os atores simulam elementos formadores da suposta cultura. 
Para Canclini, as quatro vertentes possuem conexões que levam ao entendimento do conceito de cultura. Diante da diversidade de conceitos que são atribuídos ao termo na contemporaneidade, uma definição concreta torna o debate aqui proposto mais conciso. Para tal, Geertz (1989, p. 103) é referência:

[...] o conceito de cultura ao qual eu me atenho não possui referentes múltiplos nem qualquer ambiguidade fora do comum, segundo me parece: ele denota um padrão de significados transmitidos historicamente, incorporado em símbolos, um sistema de concepções herdadas expressas em formas simbólicas por meio das quais os homens comunicam, perpetuam e desenvolvem seu conhecimento e suas atividades em relação à vida.

Assim, a cultura é uma construção histórica representada através de símbolos diversos, como exemplo, o idioma. Os aspectos linguísticos são herdados e repassados através das gerações, sofrendo mais ou menos interferências dependendo das demais influências culturais atreladas.

Assim como as culturas, a identidade é marcada também pela exclusão. A identidade é, portanto, uma afirmação de igualdade, mas também um processo de diferenciação dos desiguais. "A construção da identidade é tanto simbólica quanto social. A luta para afirmar as diferentes identidades tem causas e consequências materiais" (WOODWARD, 2000, p. 10). A identidade é representada através de símbolos culturais, portanto, a vestimenta de um indivíduo de origem alemã busca representar sua cultura, criando uma identidade germânica e excluindo as identidades francesas, italianas, americanas, etc.

As identidades também podem ser caracterizadas pela fluidez. Há diversos debates acerca do significado das identidades, analisando se o sujeito possui uma única identidade, se as múltiplas identidades se sobrepõem ou se o indivíduo incorpora uma nova identidade em cada ocasião diferente. Stuart Hall defende a existência de identidades plurais incorporadas pelos indivíduos frente às diferenças:

[...] as identidades são construídas por meio da diferença e não fora dela. Isso implica o reconhecimento radicalmente perturbador de que é apenas por meio da relação com o Outro, da relação com aquilo que não é, com precisamente aquilo que falta, com aquilo que tem sido chamado de seu exterior constitutivo, que o significado "positivo" de qualquer termo - e, assim, sua "identidade" - pode ser construído (HALL, 2000, p. 110). 
Sendo as identidades estabelecidas por meio da diferença, são elas também uma forma de segurança, de sentir-se agrupado junto aos semelhantes e distante dos demais. Esta visão da identidade como processo dependente de outros atores sociais recebe críticas a partir da visão de identidade como característica imutável inerente ao homem.

\footnotetext{
Esta abordagem que concebia a identidade cultural como praticamente imutável e determinando a conduta dos indivíduos, seria em seguida ultrapassada por concepções mais dinâmicas que não veem a identidade como um dado independente do contexto relacional (CUCHE, 1999, p. 176).
}

Em contraponto a esta percepção, Hall (1996, p. 70) afirma que "as identidades culturais são os pontos de identificação, os pontos instáveis de identificação ou sutura, feitos no interior dos discursos da cultura e da história. Não uma essência, mas um posicionamento". As identidades são criações humanas para designar comportamentos, não são como as personalidades, características psicológicas que determinam os padrões de pensamento, sentimento e ação do indivíduo.

Assim, entende-se que um mesmo indivíduo está passível de várias identificações, especialmente no contexto de fluidez contemporâneo. No entanto, há um elemento identitário originário, o qual pode apresentar-se em crise diante da multiplicidade de possibilidades de identidades disponíveis. Um exemplo disso é a identidade nacional, pois quando um sujeito migra para outra nação, pode sentir-se identificado com a nova realidade, descontextualizado ou mesmo em reafirmação de sua identidade original.

\section{MARECHAL CÂNDIDO RONDON: ASPECTOS HISTÓRICOS, CULTURAIS E IDENTITÁRIOS}

No contexto histórico do século XIX, em substituição ao trabalho escravo e indígena, incentivou-se a imigração de europeus para o Brasil, especialmente com a finalidade de servir como mão-de-obra no meio rural, de forma mais intensa nas grandes fazendas de café. A presença dos imigrantes não se deteve ao meio rural, sendo que nas cidades começavam a ser criados os núcleos coloniais, destacando-se, por exemplo, os núcleos de São Leopoldo-RS, São Pedro de Alcântara e Mafra-SC e Rio Negro-PR, no 
período entre os anos de 1824 e 1829. Dentre estes, diversos outros surgiram em várias regiões do Brasil. Dentre estes imigrantes de origem alemã, vários se tornaram proprietários de terras, e outros tantos desenvolveram atividades ligadas aos setores industriais, comerciais, educação, etc. (GREGORY, STEIN, 2011).

No caso da região Oeste do Paraná, sobretudo da atual microrregião de Toledo, os dados fornecidos pela colonizadora da época (MARIPÁ S/A) mostram uma significativa predominância de colonizadores advindos do Rio Grande do Sul e Santa Catarina, descendentes de imigrantes de origem alemã. Esses dados, no entanto, variam do local de ocupação. A região fora dividida em glebas, e dentre estas, a Gleba Céu Azul, por exemplo, detinha uma maioria significativa de descentes de italianos. Enquanto a região da Fazenda Britânia, era majoritariamente ocupada por descendentes de alemães, muito embora os atuais distritos do município tenham sido colonizados por italianos (Novo Horizonte) e Poloneses (Margarida). É relevante também destacar a constante presença de indígenas e outros indivíduos caracterizados como "brasileiros", os nacionais (GREGORY, STEIN, 2012).

A vida e a cultura destes descendentes de alemães acabaram por influenciar os modos de vida em diversos locais, sendo um deles, com maior destaque, o município de Marechal Cândido Rondon. O município em questão localiza-se no extremo oeste paranaense. A colonização da região onde se situa o município se deu através da Empresa Colonizadora denominada Industrial Madeireira Rio Paraná S/A - MARIPÁ, a partir dos anos de 1950. Quando fundada em 1951, a Colônia General Rondon teve a participação praticamente exclusiva de alemães. Segundo Stein (2000) o discurso da germanidade presente neste município se deve ao fato de que o primeiro morador, assim como os que vieram posteriormente, era um colono de origem germânica. Assim, os discursos se perpetuam nas décadas seguintes em favor de uma referência germânica ao município de Marechal Cândido Rondon.

Diversos aspectos colaboram para reforçar a visão germânica construída sobre este município, dentre eles a arquitetura característica presente no portal de entrada. No local onde está localizado o portal de entrada do município, havia dois troncos desde 1978, quando o trevo de acesso à cidade foi inaugurado. As madeiras representavam as riquezas naturais da região. Para Gregory; Stein (2012), os troncos representavam um "lugar de memória" para a população, sendo posteriormente substituídos por outro 
símbolo, que seria o atual portal da cidade, representado por traços da arquitetura germânica, anunciando aos visitantes o que supostamente encontrarão ao adentrar a cidade.

Imagem 1: Portal de entrada de Marechal Cândido Rondon em visão noturna.

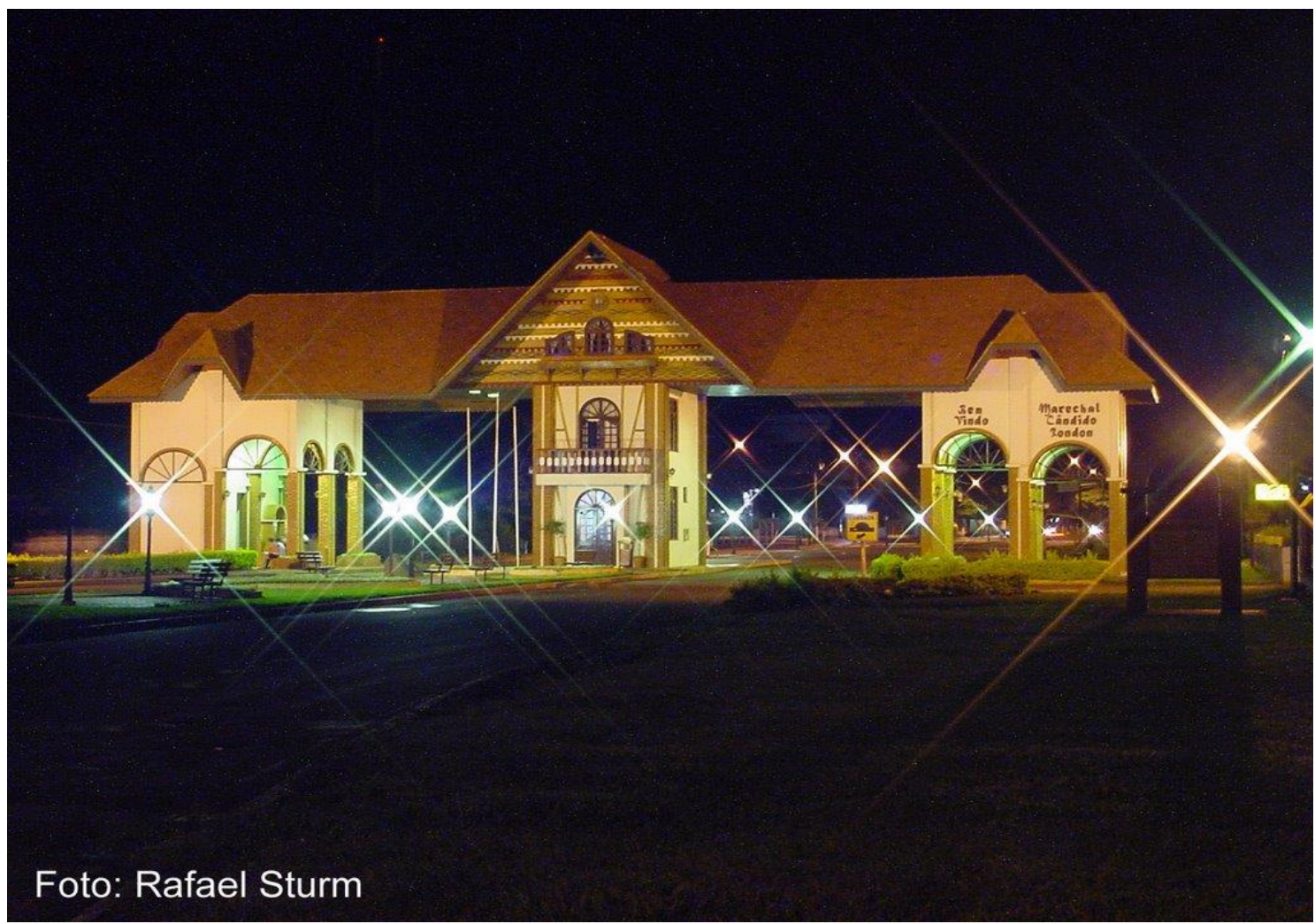

Fonte: https://mapio.net/images-p/2457076.jpg

Diversas são as construções que se remetem à germanidade, principalmente em empresas da região central da cidade, mas também moradias particulares. Duas construções principais podem ser destacadas: a casa da Família Seyboth e a casa de Heribert Hans Joachim Gasa, sendo que ambas foram apresentadas em reportagem produzido pela RPC-TV (CASA, 2012). Em entrevista na época, Gasa afirmou: "podese dizer que minha casa é uma miscelânea de culturas. Há traços gregos, germânicos, italianos, astecas, entre outros" (MEINERZ; STEIN, 2009, p. 1025).

A casa e a vida de Hans Gasa talvez sejam os aspectos mais curiosos de Marechal Cândido Rondon, devido aos imaginários criados acerca deste sujeito e sua misteriosa forma de viver. Atualmente a residência foi transformada em um ambiente 
comercial, primeiramente em um bar, denominado "Bunker Berlin", depois "Barão Bunker", também indicativo das memórias relativas à germanidade, já que os bunkers redutos fortificados - são historicamente comuns na Alemanha.

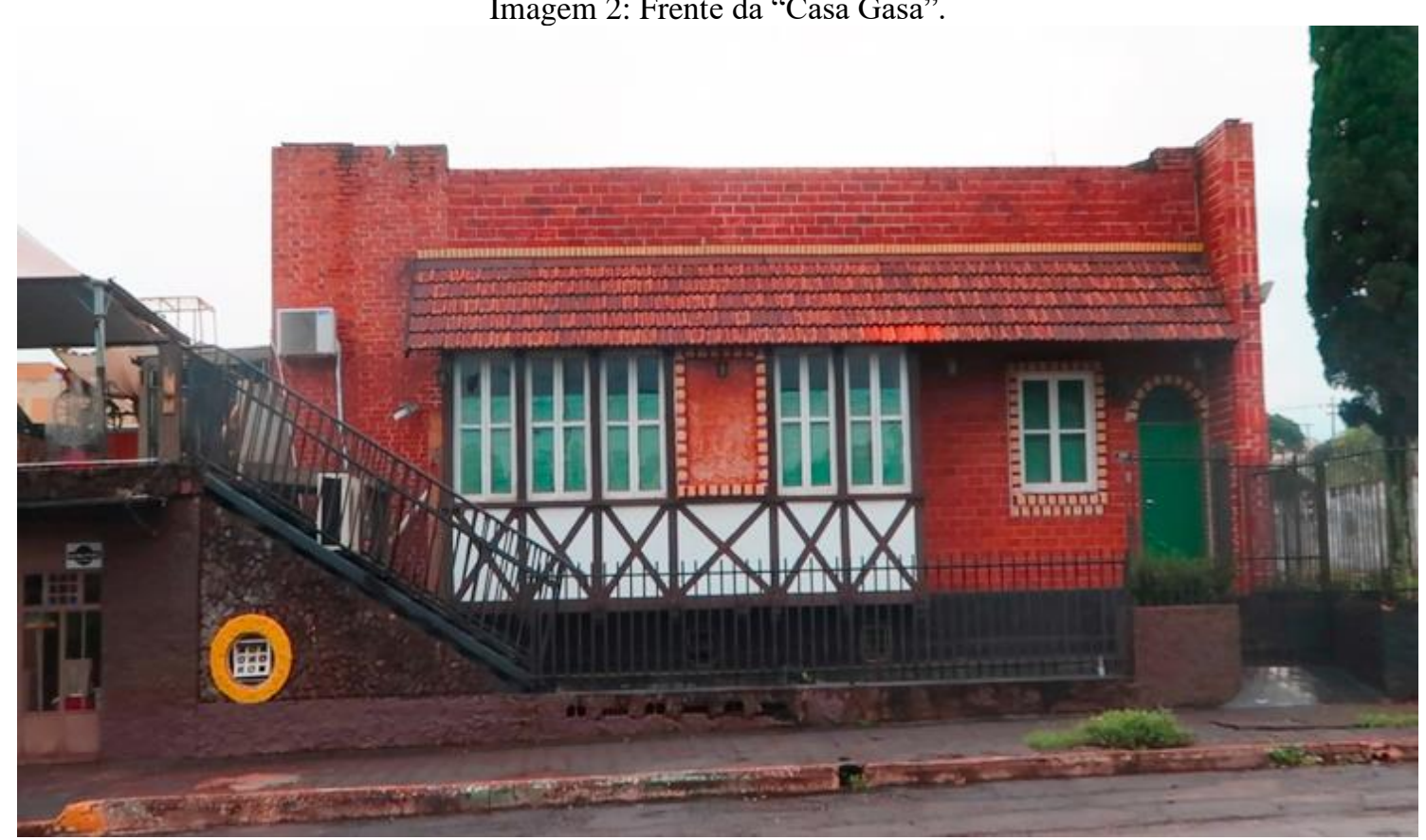

Fonte: https://www.temperosdavida.com/cotidiano/conheca-a-cidade-paranaense-que-preserva-a-culturaalema-e-pode-ter-abrigado-hitler.

Para além das construções típicas, a linguagem dos rondonenses mostra a ligação com a cultura germânica, fator evidenciado através do sotaque. A pronúncia de algumas palavras é tão interessante aos "outros" que promoveu o surgimento de um comediante rondonense, conhecido em diversos estados brasileiros pela incorporação do personagem "alemão colono" - no sentido de indivíduo que vive no campo, trabalhando na lavoura e pecuária, evidenciando o sotaque alemão, de um modo adaptado - comum em Marechal Cândido Rondon. O personagem, no caso, ficou conhecido como Willmutt (nome comum alemão), o qual veio a falecer, vítima de um acidente, no ano de 2015.

Imagem 3: Personagem Willmutt, que fazia referência aos traços da cultura germânica de Marechal Cândido Rondon. O personagem ficou especialmente conhecido pelos trotes e pegadinhas que fazia, 
usando linguagem comum entre os descendentes de alemães da cidade.

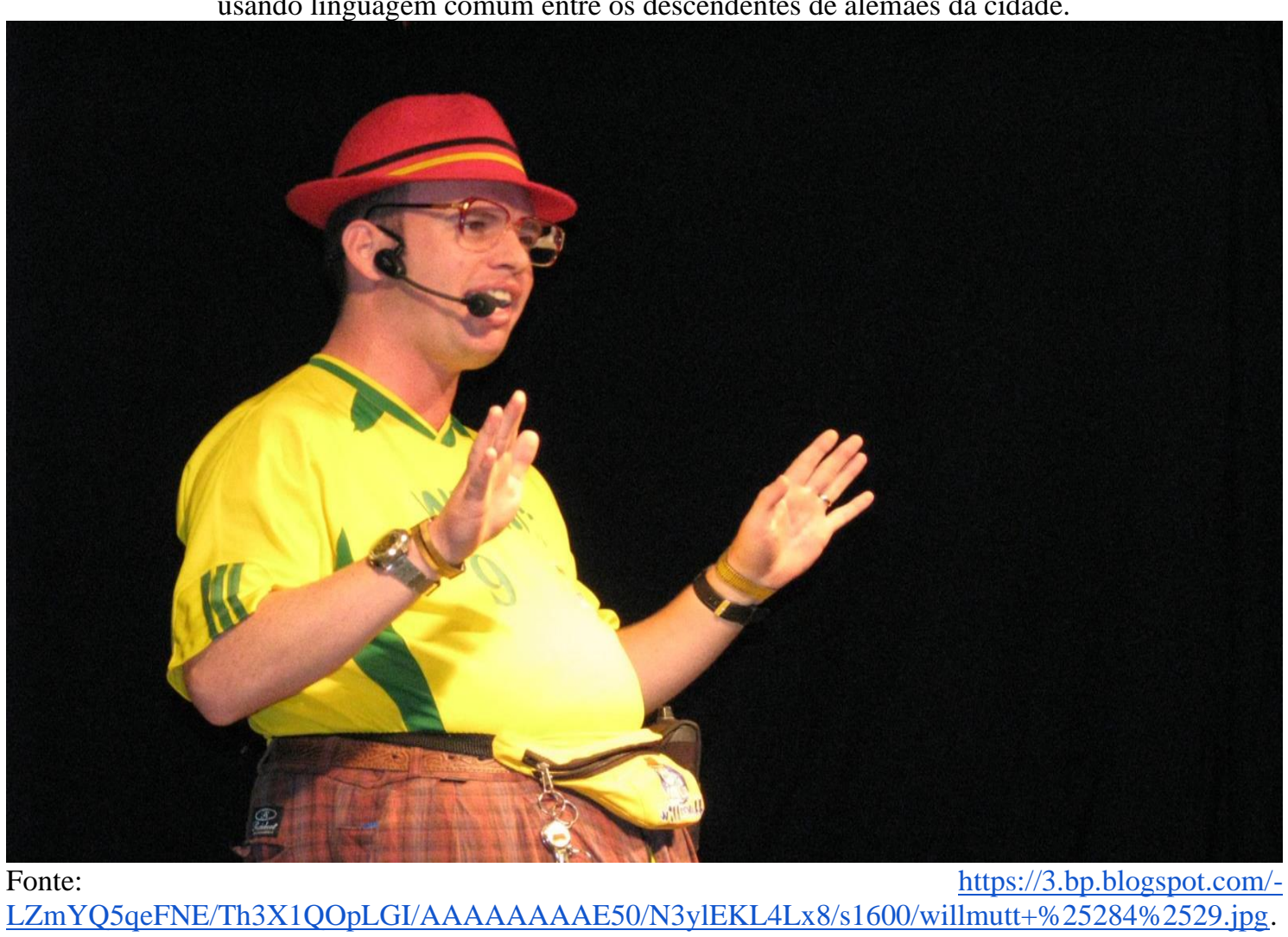

Assim como em Blumenau em Santa Catarina, a Oktoberfest é também uma festa típica de Marechal Cândido Rondon. Esta festa tem como intenção relembrar os costumes germânicos através do consumo de Chopp e de alimentos característicos, como eisbein, salsichões e chucrute, além de outros. As festividades se perpetuam ao longo do tempo, apesar de algumas críticas em relação a esta festa, alegando que ela se tornou apenas mais um evento com finalidade mercadológica, sem que haja uma ligação verídica com as origens alemãs.

O centro de eventos de Marechal Cândido Rondon, que é palco da Oktoberfest, é também caracterizado com traços da cultura germânica, em estilo enxaimel. Juntamente à constituição da festa, criou-se a imagem do "Opa Fass", representado pelo morador da cidade Hélio Zachow, falecido em 2003. A figura do alemão gordo, de barba branca, alegre e tomador de chopp, foi por muitos anos a marca da festa. Um memorial foi construído junto ao Centro de Eventos Werner Wanderer em homenagem ao Opa Fass. 


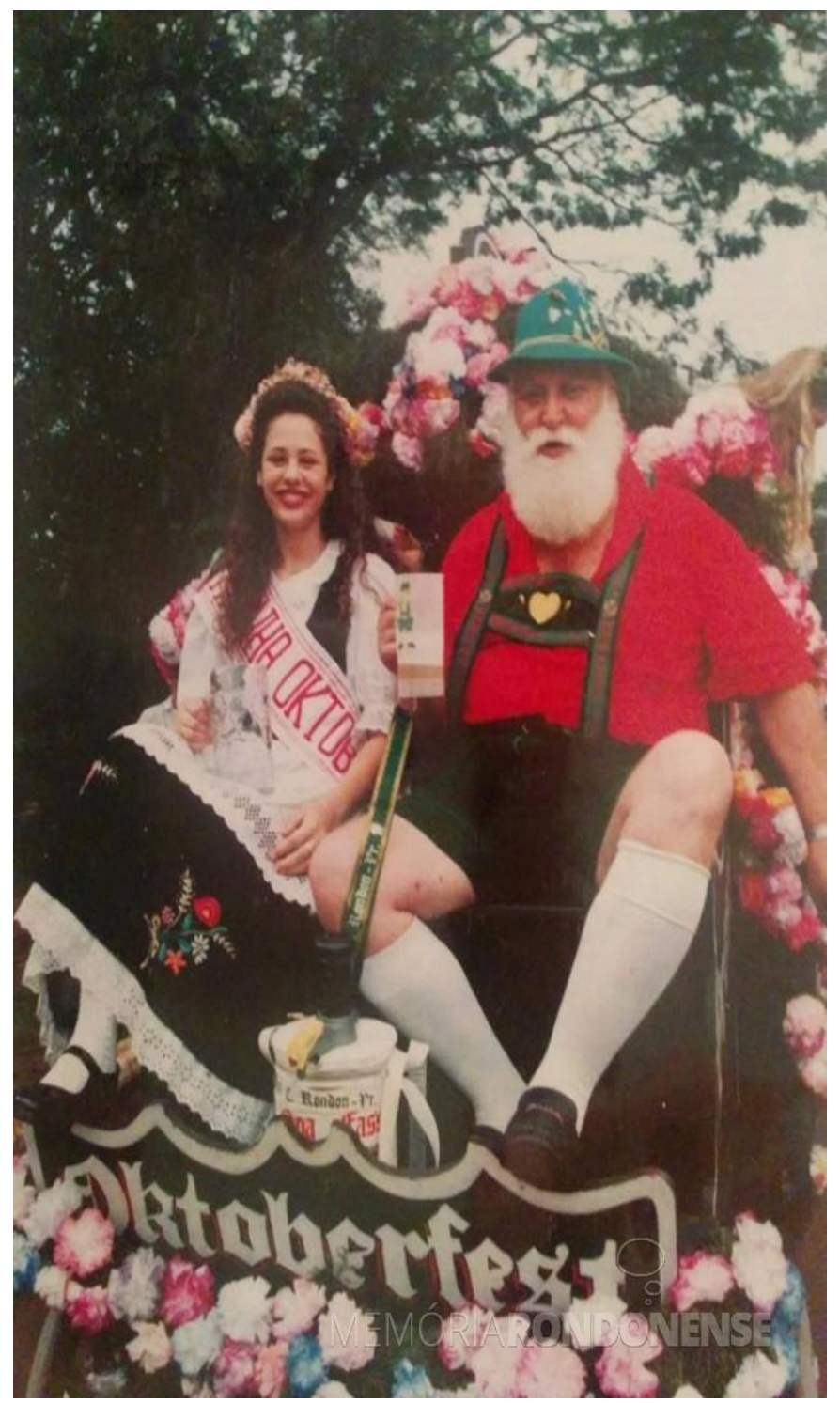

Fonte:

https://www.memoriarondonense.com.br/public/timthumb.php?w=780\&src=http://www.memoriarondone nse.com.br/public/upload/calendario-

historico/2ad092fe7f6eaae7b825b4d53393fb8d.jpg\&m=img/65.png\&p=2\&ct=1.

Além da Oktoberfest, é expressiva em Marechal Cândido Rondon a "Festa Nacional do Boi no Rolete", realizada em comemoração ao aniversário de emancipação do município. A festa onde o boi inteiro é assado no rolete pode ser caracterizada, pelas concepções de Hobsbawm (1984), como uma tradição inventada. A incorporação de traços culturais ou costumes não originários do lugar, representam a invenção de uma tradição, a incorporação e assimilação destes aspectos se torna fiel de um modo que em muitos casos passam a ser vistos como próprios daquele povo. Assim, o elemento cultural não é obrigatoriamente de origem germânica, mas foi incorporado aos demais 
elementos culturais municipais, se confundindo, por vezes, com os aspectos germânicos. É, portanto, um exercício de complexidade definir o que é cultura original e o que é incorporado ao ambiente cultural.

A preservação de traços culturais germânicos em Marechal Cândido Rondon não é em sua integridade um aspecto natural, mas também planejado por alguns setores da sociedade. Para os indivíduos comuns, o "ser germânico" não costuma ser algo refletido, simplesmente vivem as características culturais que herdaram historicamente. "A identidade é irrevogavelmente uma questão histórica. Nossas sociedades são compostas não de um, mas muitos povos. Suas origens não são únicas, mas diversas" (HALL, 2003, s/p.). Esse fator é responsável pelo hibridismo cultural, característico principalmente frente ao fenômeno da globalização.

É evidente a presença de outros grupos étnicos em Marechal Cândido Rondon, mas a predominância alemã ainda é muito intensa, motivo que faz reviver constantemente às origens e os costumes relacionados à germanidade. A própria Prefeitura Municipal de Marechal Cândido Rondon, em seus documentos voltados ao turismo, apresenta uma informação que busca prontamente mostrar quem são os rondonenses: "Marechal Cândido Rondon é uma cidade típica germânica onde os traços do povo e as construções enxaimel [tipo de arquitetura típica alemã] preservam a cultura europeia" (MARECHAL CÂNDIDO RONDON, 2020). A naturalização da arquitetura germânica construiu-se gradativamente, uma vez que não foi um processo totalmente espontâneo. Através de incentivos, como redução dos impostos, os comerciantes e moradores da cidade "optaram" pelas fachadas em estilo enxaimel. Essa medida estava atrelada ao Projeto de Caracterização Germânica de Mal. Cdo. Rondon. 


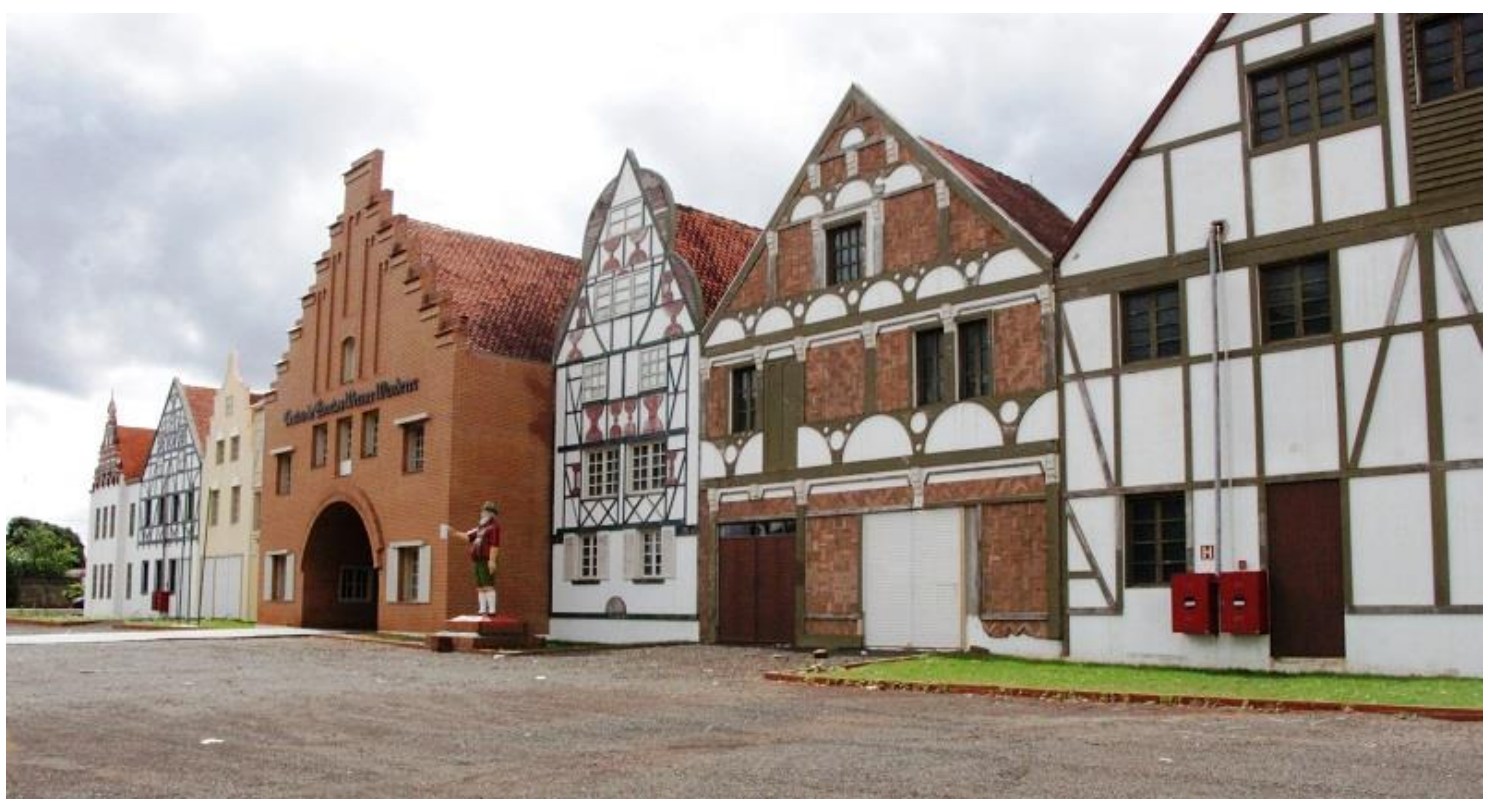
tematico-inspirado-cultura-alema-marechal-rondon.jpg.

É relevante destacar que, embora os discursos da colonização do Oeste paranaense relevem em especial o protestantismo, a influência de alemães católicos também foi expressiva. De acordo com Deitos (2007, p. 183), durante o período de colonização do Oeste paranaense, a Igreja Católica desenvolveu "uma estratégia ímpar junto aos colonos, a fim de provê-los dos 'bens espirituais'. Ao mesmo tempo, construiu a imagem do colono enquanto um homem abnegado ao trabalho e voltado aos interesses da coletividade". Portanto, não se pode negar a presença e influência católica na constituição da região. Em Marechal Cândido Rondon especificamente predominavam os protestantes, presença fortemente percebida até os dias atuais.

Quanto ao protestantismo, Gregory; Stein (2012) afirmam que a formação de uma rede de igrejas luteranas relacionada à colonização, inclusive com instituições próprias de apoio aos colonos (como o CAPA - Centro de Apoio e Promoção da Agroecologia), dá margem ao discurso do protestantismo alemão. Ambos, católicos e luteranos, aderiram a imagem e o discurso do labor dos imigrantes no processo de colonização regional. Essa dimensão do trabalhador, tanto católico, mas principalmente protestante, foi descrita na obra de Max Weber (2004) “A ética protestante e o espírito do capitalismo", que após o século XVI (resultante da Reforma Protestante por Martinho Lutero e seguido por João Calvino) dispõe sobre uma ética do trabalho, a qual se baseia na dedicação que os trabalhadores em sua busca pela graça e salvação 
alcançariam por meio da disciplina que estes teriam com o labor. $\mathrm{O}$ estado de graça agora poderia ser perceptível em vida como o resultado da acumulação da riqueza gerada pelo trabalho.

Devido à força da cultura germânica, os demais grupos étnicos são, em alguns momentos, colocados em posições de menor destaque social, até mesmo com dificuldades de integração. O estudo de Elias (2000) analisa os "estabelecidos" e os "outsiders", e permite uma reflexão sobre as limitações da integração de sujeitos descendentes de outras etnias na comunidade rondonense. Neste sentido, os estabelecidos em Marechal Cândido Rondon são aqueles indivíduos que estão envoltos na cultura germânica, enquanto os outsiders $^{3}$ são aqueles sujeitos que vieram à cidade em períodos posteriores à colonização, trazendo consigo aspectos culturais diversos daqueles já estabelecidos. Mesmo que nem sempre tão evidentes, as tentativas de integração em uma sociedade com perfil cultural mais conservador, podem ser geradoras de preconceitos ou marginalização social.

De outro lado, os descendentes de alemães de Marechal Cândido Rondon também são vítimas de chacotas por parte de outros indivíduos, uma vez que são um conjunto com características específicas dentro da sociedade. O preconceito é principalmente devido à fala engraçada, vestimentas e demais práticas culturais. Os preconceitos são aspectos que podem estar presentes na sociedade motivados por um estranhamento entre os grupos sociais, assim como as concepções e valores consolidados na consciência coletiva destes. Assim, mesmo em meio aos descendentes de alemães de Marechal Cândido Rondon é possível perceber a discriminação quanto ao modo de falar, principalmente devido à mistura de português com dialetos alemães, como o Hunsrückisch ${ }^{4}$ e o Pomerano.

\footnotetext{
3 Nas décadas anteriores houveram diversas migrações para a cidade de Marechal Cândido Rondon estimuladas por nascentes agroindústrias na busca de oportunidades de trabalho. Bairros ao redor destas empresas se formaram com uma etnografia peculiar aos bairros mais antigos e centrais, pois estes seriam formado majoritariamente pessoas oriundas dos demais estados brasileiros e do Paraná. Recentemente a cidade de Marechal Cândido Rondon viu-se diante da presença de uma nova leva de outsiders, primeiramente haitianos e mais tarde africanos e asiáticos que estão residindo na cidade e trabalhando sobretudo na agroindústria. Em uma cidade que se declara predominantemente germânica não se torna difícil perceber a presença dos outros sujeitos que compõe a população.

${ }^{4}$ Boa parte dos descendentes de alemães que vivem no Brasil são bilíngues, falando tanto o português quanto o dialeto pomerano - Pommersch ou Pommersch Platt - ou o Hunsrückisch. Os falantes do Pomerano são originários da região norte da Alemanha, que era conhecida como Pomerânia. Estes estão estabelecidos em algumas regiões do país, inclusive em Marechal Cândido Rondon. O Hunsrückisch é também conhecido no Brasil como "Riograndenser Hunsrückisch". Conforme Von Borstel (2012) o
} 
Para Gregory; Stein (2012), com o advento da expansão do acesso aos programas televisivos e o conhecimento de outras culturas, houve, principalmente entre os jovens a criação de um sentimento de desprezo pela cultura e a forma de ser dos alemães, em especial em relação à linguagem. Considerados grosseiros, ultrapassados e mal educados, os descendentes de alemães, principalmente moradores do campo, sofrem grande preconceito.

Aspectos diversos são relacionados à cultura germânica, como alguns alimentos tradicionais que são consumidos por grande parte dos rondonenses, como a cuca e a linguiça. Além disso, existem grupos especializados em danças típicas alemãs, que em Marechal Cândido Rondon se destaca a "Associação de Danças Folclóricas Germânicas Raízes", este representa músicas e vestimentas típicas, sendo que mesmo as crianças podem ter acesso ao estilo de dança, incorporando tais elementos culturais.

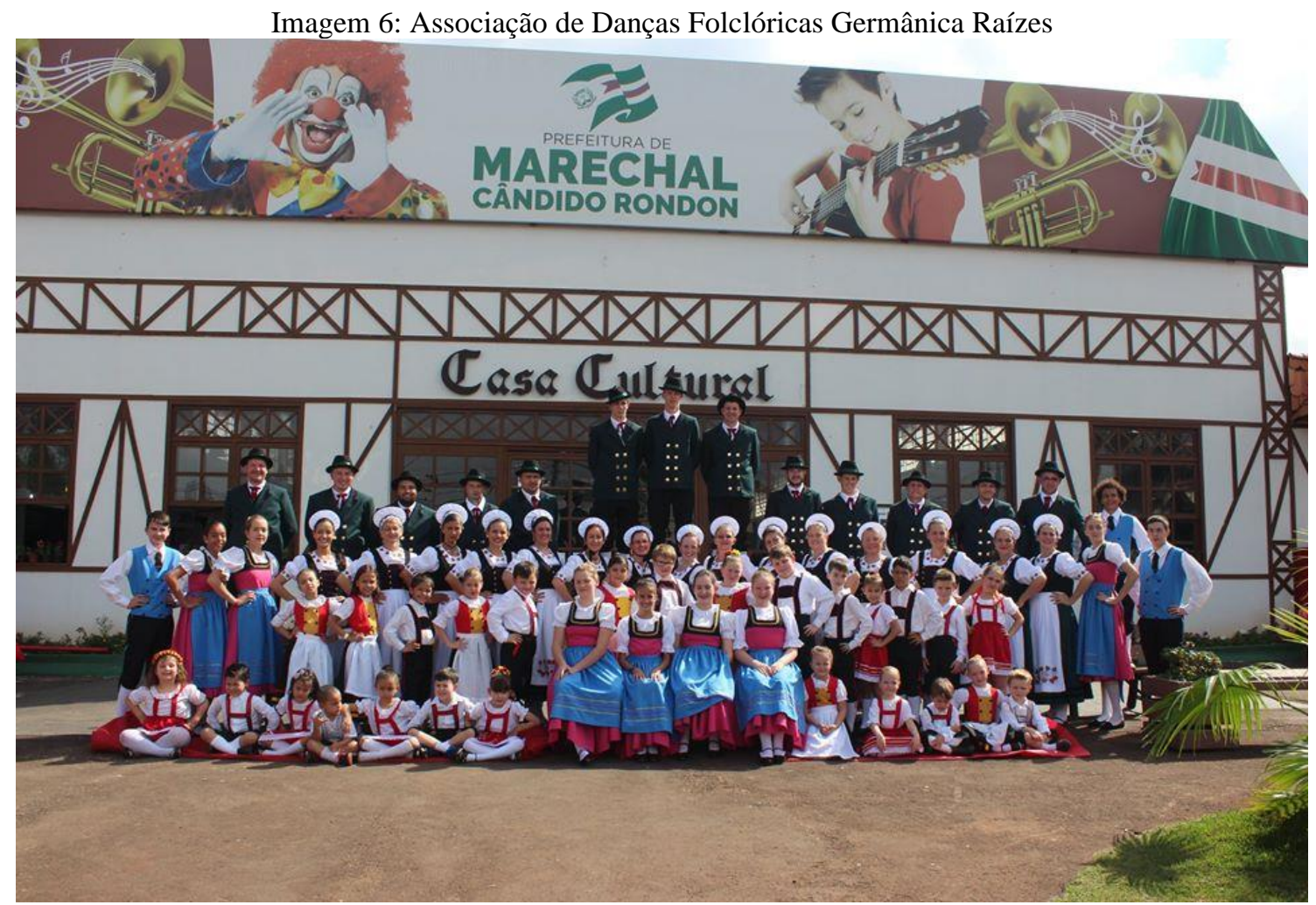
0/p640x640/39883673_2195748433974796 486347854487486464_o.jpg?_nc cat=102\&_nc_sid=dd980 1\&_nc eui2=AeHRF6sJ9HQcOWLmrv63QZZ97fntgHJNud7t-

Hunsrückisch ainda é falado na cidade de Marechal Cândido Rondon, especialmente nas vilas de Iguiporã e Bom Jardim, mas também entre os moradores da área urbana da cidade. $\mathrm{O}$ dialeto difundiu-se através dos imigrantes que vieram da região do Hunsrück, na Alemanha. 
e2Ack253tZY95kNoZQYA4VDVO5zTTzJIpZZVyfDIDeGP13uxqqh\&_nc_ohc=tBdAF0dHz7AAX8eh Ry-\&_nc_ht=scontent.fgel2-1.fna\&_nc_tp=6\&oh=e0acca414a1c078fc2fbbf3b928820c5\&oe=5F00C95F

Em especial no Oeste paranaense, a influência dos alemães foi muito intensa no período da colonização. Os imigrantes alemães difundiram no Brasil a religião protestante, foram fortes impulsores da agricultura familiar que perdura até hoje, introduziram o cultivo de espécies como o trigo e ainda a criação de animais, como os suínos. Fatores estes que contribuem para a formação de um discurso favorável aos alemães como povo trabalhador, que não tem preguiça de trabalhar para conquistar seus objetivos. Os estereótipos que são atribuídos aos imigrantes alemães são variados, havendo uma crítica quanto à rispidez destas pessoas, o tom de voz alto e as festas animadas com muita cerveja, ou Chopp.

Em Marechal Cândido Rondon é possível perceber o orgulho que alguns sujeitos sentem em dizer que são de origem alemã. Através disso ficam evidentes os motivos que levam os munícipes e o Poder Público a manter viva a cultura germânica.

[...] a cultura não é apenas uma viagem de redescoberta, uma viagem de retorno. Não é uma "arqueologia". A cultura é uma produção. Tem sua matéria-prima, seus recursos, seu "trabalho produtivo". Depende de um conhecimento da tradição enquanto "o mesmo em mutação" e de um conjunto efetivo de genealogias. Mas o que esse "desvio através de seus passados" faz é nos capacitar, através da cultura, a nos produzir a nós mesmos de novo, como novos tipos de sujeitos. Portanto, não é uma questão do que as tradições fazem de nós, mas daquilo que nós fazemos das nossas tradições (HALL, 2003, [s/p]).

É assim um processo mútuo, onde os indivíduos preservam os traços culturais pelo fato de sentirem laços com estes. Mas, também são artimanhas para se autoafirmar como sujeitos, pertencentes ao grupo dos descendentes de alemães, neste caso.

Ao se refletir sobre a Oktoberfest como uma das manifestações da cultura germânica, por exemplo, é possível perceber como as fronteiras são fluidas. A presença de pessoas originárias de outras etnias é muito forte neste espaço festivo, são múltiplas as culturas que se reúnem com um objetivo comum: diversão. Mas nem todos sabem qual o significado de uma festa como esta, que originalmente teria como motivação uma lembrança dos costumes germânicos, a celebração da presença germânica no Brasil. 
Portanto, a territorialidade criada em favor dos indivíduos germânicos recebe influências de outras culturas, permite o contato com outras manifestações culturais, tornando-se flexível. Outro exemplo é a incorporação de comidas típicas brasileiras ou de outros países, que não a Alemanha, de modo a agradar todos os gostos dos turistas que participam das festividades.

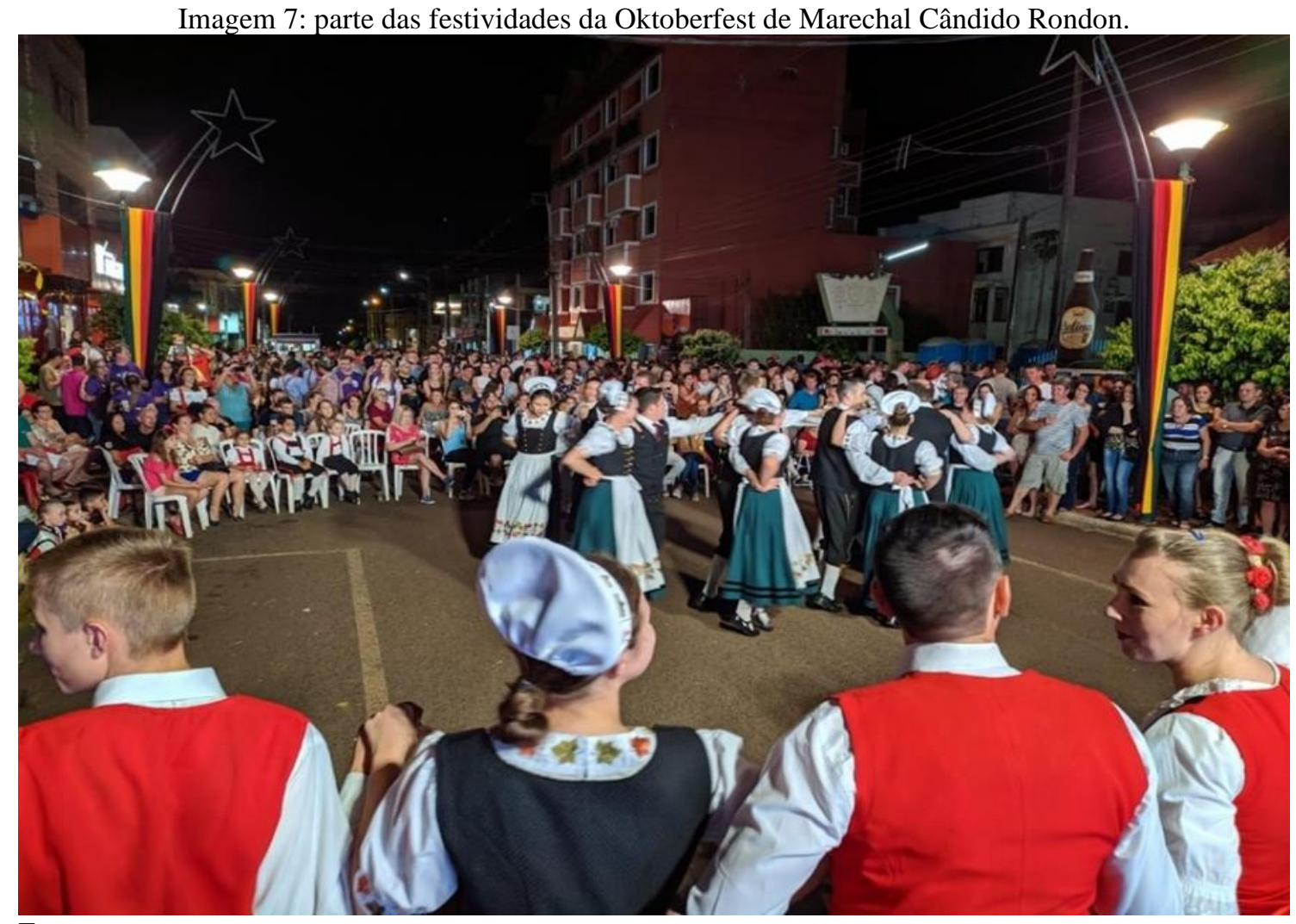

Fonte:

https://www.aquiagora.net/images/grande/2/25d8f5ddb23f1e_71027749_2600099590036061_757083274 9234225152_n.jpg.

Em 2012 houve o lançamento do livro intitulado "Imigração Alemã no Paraná: 180 anos", o qual aborda em um dos capítulos a germanidade no Oeste paranaense, em especial na cidade de Marechal Cândido Rondon, resgatando as memórias dos pioneiros da cidade, e construindo os aspectos que levam a caracterização da identidade germânica da região. Para os autores do capítulo em questão, "a germanização em Marechal Cândido Rondon intitula o debate sobre a construção de uma identidade vinculada à exploração turística local em que é estruturado um projeto de caracterização da sociedade de Marechal Cândido Rondon” (GREGORY; STEIN, 2012, p. 347). Neste 
sentido, o aspecto germanidade é atribuído de valor mercadológico, recebendo aceitação social e promovendo a venda desta característica.

O intuito econômico do turismo pôde ser percebido desde a elaboração do Projeto de Caracterização Germânica de Mal. Cdo. Rondon, quando a base para a concretização do projeto era o crescimento da economia como visto em Blumenau em Santa Catarina, por meio dos aspectos europeus incorporados por esta, que atraem um grande fluxo de turistas todos os anos, principalmente com a Oktoberfest de Blumenau. Sobre isso, discorrem Gregory; Stein (2012, p. 362):

Em Marechal Cândido Rondon, lançou-se mão de vários discursos presentes na cidade [...] como a valorização do discurso sobre o caráter laborioso e ordeiro de sua população formada majoritariamente por descendentes de imigrantes alemães e a desclassificação de outros discursos que representam a negatividade de outra parcela da população.

Com isso, faz-se pertinente a argumentação da característica germânica enquanto identidade de Marechal Cândido Rondon. Há, na atualidade, uma imensa quantidade de identidades que precisam ser incorporadas diariamente pelos sujeitos sociais. O indivíduo germânico é assim percebido em momentos peculiares, cotidianamente ele é trabalhador, pai, protestante, católico, político, estudante, marido, amigo, etc. São as múltiplas identidades que dão forma ao sujeito. As identidades são assim representações.

\footnotetext{
A representação inclui as práticas de significação e os sistemas simbólicos por meio dos quais os significados são produzidos, posicionando-nos como sujeito. É por meio dos significados produzidos pelas representações que damos sentido à nossa experiência e àquilo que somos" (WOODWARD, 2000, p. 17).
}

Assim, a germanidade é, acima de tudo, uma representação simbólica. O estabelecimento de uma identidade. Aliás, pensar sobre a identidade nem sempre foi um aspecto importante na Ciência, cientistas acreditavam que não havia necessidade de criar este tipo de reflexão. A identidade não é algo natural ao homem, mas uma ideia que foi lançada ao pensamento humano, e como outros conceitos, enfrenta dificuldades em suas definições. 


\begin{abstract}
A identidade - sejamos claros sobre isso - é um "conceito altamente contestado". Sempre que se ouvir essa palavra, pode-se estar certo de que está havendo uma batalha. O campo de batalha é o lar natural da identidade. Ela só vem à luz no tumulto da batalha, e dorme e silencia no momento em que desaparecem os ruídos da refrega (BAUMAN, 2005, p. 85).
\end{abstract}

Mas não somente no campo dos conceitos a identidade enfrenta contradições. $\mathrm{Na}$ prática, cobra-se muito dos indivíduos uma identidade que seja adequada à sociedade. "A tarefa de construir uma identidade própria, torná-la coerente e submetê-la à aprovação pública exige atenção vitalícia, vigilância constante, um enorme e crescente volume de recursos e um esforço incessante sem esperança de descanso" (BAUMAN, 2005, p. 89). Uma vez construída a identidade, ela deve ser mantida com zelo para que não venha a parecer desvalorizada frente aos demais sujeitos. Assim, tudo o que é germânico é bem aceito e mais valorizado por aqueles indivíduos que se consideram portadores de uma identidade germânica.

As identidades são frágeis ao mesmo tempo em que representam rigidez. Frágeis, pois recebem interferências externas, de culturas variadas e parece que sempre precisam ser reafirmadas. Rígidas, pois resistem ao fenômeno da globalização e a facilidade de contato entre os elementos culturais mais diversos. As fronteiras entre os estabelecidos e os outsiders são instáveis, representam momentos de flexibilidade e de tensão, dependendo da ocasião. Assim, a identidade é várias coisas em uma apenas: segurança, instabilidade, afirmação, desigualdade, pertencimento, exclusão. Cultura e identidade estão intimamente relacionadas, interligadas de modo que uma representa a outra.

\title{
CONSIDERAÇÕES FINAIS
}

Discutir o tema "identidade" é uma tarefa um tanto difícil, principalmente no período contemporâneo, quando o mundo se torna "pequeno" diante dos avanços tecnológicos alcançados. Os indivíduos precisam desenvolver e flexibilizar as múltiplas identidades de que necessitam ocasionalmente. Surgem questões diversas quanto à existência de uma identidade dominante, sobreposição de identidades, pertencimento ou exclusão. 
É pertinente compreender que não há uma única identidade atribuída ao indivíduo, mas sim múltiplas. Identidades estas que se revelam frente às ocasiões onde o indivíduo precisa se impor de alguma forma, assumir um "papel". Assim, uma mulher é mãe durante a noite, mas sua identidade de trabalhadora se reforça durante o dia. Porém, em momento algum ela deixa de ser mãe e trabalhadora. Portanto, as pessoas convivem com identidades diversas, onde cada uma se desenvolve no momento necessário.

Marechal Cândido Rondon é um município de cultura variada, sendo possível perceber a presença de diversos grupos étnicos. Mas, a marca da cultura germânica ainda se faz muito presente neste lugar, de modo que as manifestações sociais sejam favoráveis à conservação desta cultura. É difícil afirmar se esta cultura germânica é imposta de alguma forma no pensamento dos rondonenses, de modo a construir uma identidade. Ou, se cotidianamente essa cultura é construída naturalmente através dos atos individuais.

Os símbolos que apresentam Marechal Cândido Rondon como germânica, são os mesmos que a colocam em uma posição de exclusão das demais culturas. Porém, é relevante compreender que embora culturalmente o município seja de origem germânica, a contribuição dos demais grupos étnicos foi significativa na construção histórica do município. Neste sentido, a questão não se esgota, existe uma identidade dominante? Qual a identidade de Marechal Cândido Rondon? É, neste sentido, importante refletir que os indivíduos que vivem diariamente nesta cidade dificilmente se flagrarão pensando em sua identidade, vivem e convivem com identidades múltiplas, contornam obstáculos e preconceitos, relacionam-se sem a preocupação consciente de definir-se como alemão, italiano, polonês, haitiano, brasileiro, etc.

\section{REFERÊNCIAS BIBLIOGRÁFICAS}

BAUMAN, Zygmunt. Identidade: entrevista a Benedetto Vecchi. Rio de Janeiro: Jorge Zahar, 2005.

CANCLINI, Néstor García. Diferentes, desiguais e desconectados: mapas da interculturalidade. 3. ed. Rio de Janeiro: Editora UFRJ, 2009.

CUCHE, Denys. A noção de cultura nas Ciências Sociais. Bauru: EDUSC, 1999. 
DEITOS, Nilceu Jacob. A Igreja Católica no oeste do Paraná e sua atuação no processo de colonização. In: VANDERLINDE, Tarcísio; GREGORY, Valdir; DEITOS, Nilceu Jacob. Migrações e a construção do oeste do Paraná: século XXI em perspectiva. Cascavel: Coluna do Saber, 2007. p. 183-189.

ELIAS, Norbert. Os estabelecidos e os Outsiders. Rio de Janeiro: Jorge Zahar, 2000.

G1. Casa construída por alemão que lutou na $2^{\text {a }}$ Guerra é cenário de lendas: Imóvel começou a ser construído em 1966 e levou 20 anos até ficar pronto. Residência em Marechal Rondon (PR) tem alçapões e passagens secretas. Curitiba: RPC, 2014. Disponível em: <http://g1.globo.com/pr/oestesudoeste/noticia/2014/08/casa-construida-por-alemao-que-lutou-na-2-guerra-e-cenariode-lendas.html > . Acesso em: 05 de jun. de 2020.

GEERTZ, Clifford. A Interpretação das Culturas. Rio de Janeiro: Guanabara Koogan, 1989.

GREGORY, Valdir; STEIN, Marcos Nestor. Migrações e Germanidade: Oeste do Paraná e Marechal Cândido Rondon. In: VITECK, Harto. Imigração Alemã no Paraná: 180 anos. Marechal Cândido Rondon: Editora Germânica, 2012. p. 347-382.

HALL, Stuart. Identidade Cultural e Diáspora. Revista do Patrimônio Histórico e Artístico Nacional, n.24, p. 68-75, 1996.

, Stuart. Quem precisa da identidade? In: SILVA, Tomaz Tadeu da (org.). Identidade e Diferença: A perspectiva dos estudos Culturais. Rio de Janeiro: Vozes, 2000 .

Stuart. Da diáspora: Identidades e mediações culturais. Belo Horizonte: Editora UFMG, 2003.

HOBSBAWM, Eric. "Introdução" In: HOBSBAWM, Eric. RANGER, Terence. A invenção das tradições. Rio de Janeiro: Paz e Terra, 1984, p. 9-23.

MARECHAL CÂNDIDO RONDON, Prefeitura Municipal [site antigo]. Disponível em <http://antigo.mcr.pr.gov.br/nossacidade>. Acesso em: 05 de jun. de 2020

MEINERZ, Marcos Eduardo; STEIN, Marcos Nestor. Os caçadores de nazistas em Marechal Cândido Rondon-PR. In: CONGRESSO INTERNACIONAL DE HISTÓRIA, 4., 2009, Maringá. Anais [...]. Maringá: UEM, 2009.

VON BORSTEL, Clarice Nadir. A alternância lexical do Brasildeutsch. Disponível em: <https://webs.ucm.es/info/especulo/numero45/bradeutc.html>. Acesso em: 05 de jun. de 2020 .

WEBER, Max. A ética protestante e o espírito do capitalismo. São Paulo: Companhia das Letras, 2004. 
WOODWARD, Kathryn. Identidade e diferença: uma introdução teórica e conceitual. In: SILVA, Tomaz Tadeu da (org.). Identidade e Diferença: A perspectiva dos estudos Culturais. Rio de Janeiro: Vozes, 2000. 